\title{
Local variations in protein structure in the human eye lens: a Raman microspectroscopic study
}

\author{
Marianne H. Smeets ${ }^{\text {a,b }}$, Gijs F.J.M. Vrensen ${ }^{a}$, Kees Otto ${ }^{b}$, Gerwin J. Puppels ${ }^{b}$ \\ and Jan Greve ${ }^{b}$ \\ ${ }^{a}$ Department of Morphology, The Netherlands Ophthalmic Research Institute, Amsterdam (The Netherlands) and \\ ${ }^{b}$ Department of Applied Physics, Twente University of Technology, Enschede (The Netherlands)
}

(Received 15 October 1992)

(Revised manuscript received 4 February 1993)

Key words: Protein conformation; Raman spectroscopy; Lens; Aging; (Human); (Eye)

Confocal Raman microspectroscopy was used to monitor local and age-related changes in protein conformation in human eye lenses. In clear human lenses of varying age (range 17-80 years) spectra were recorded along the visual axis, using laser light of $660 \mathrm{~nm}$ wavelength. The Raman vibrations in the $650-1750 \mathrm{~cm}^{-1}$ spectral region were analyzed. Difference spectra between central core and different positions along the visual axis were calculated after calibration for protein content using the I(1450) $\mathrm{cm}^{-1} \mathrm{CH}_{2} / \mathrm{CH}_{3}$ vibration peak. Tryptophan content was quantified using the peak at $760 \mathrm{~cm}^{-1}$ calibrated for protein. Changes in the 'exposed' vs. 'buried' position of tryptophan were analyzed using the peak heights at $I(880)$ and $I(760) \mathrm{cm}^{-1}$. The difference spectra revealed an excess of tryptophan, tyrosine, phenylalanine, $\beta$-sheet conformation and molecules or molecular groups responsible for a $1425 \mathrm{~cm}^{-1}$ peak in the core region in all lenses investigated. The excess peaks disappeared at about $0.6-0.9 \mathrm{~mm}$ below the surface. The tryptophan content increased from superficial to deep layers, levelling off between $0.4-0.8$ $\mathrm{mm}$ below the surface. Upon aging, the tryptophan content increases in the core not in the cortex. No changes in the 'exposed' vs. 'buried' position of tryptophan were observed. Changes in tryptophan and tyrosine probably reflect the maturational shift from cortex to core in the relative content of $\alpha, \beta$ and $\gamma$ crystallines. The age-related increase in tryptophan in the core may reflect the preferential breakdown by endo- and exopeptidases of $\alpha$-crystallins damaged upon aging. The increase in $\beta$-sheet conformation may indicate a post-translational shift in secondary conformation upon aging. These changes in protein conformation are largely completed in a small superficial zone, i.e., in the early life span of the crystallins.

\section{Introduction}

Aging of the human eye lens is accompanied by a decrease in nuclear protein content [1] and changes in crystallin composition and macromolecular conformation of proteins [2-7]. Conformational protein changes, including dehydration/hydration, formation of aggregates, changes in backbone and side-chains are early signs of increased light scatter, possibly preluding cataract formation. Especially the protein side-chain groups cysteine, tryptophan and tyrosine are thought to play a crucial role in the formation of protein aggregates [8-11].

To understand the process of lens aging it is important to elucidate the physico-chemical events occurring in proteins at the macromolecular level. Since the fiber

Correspondence tu: G.F.J.M. Vrensen, Department of Morphology, The Netherlands Ophthalmic Research Institute, P.O. Box 12141, 1100 AC Amsterdam, The Netherlands. cells and the epithelial cells, from which the first originate, exist throughout life, the lens comprises 'old' post-translationally-altered crystallins in the core and newly synthesized crystallins in the cortex. In a previous Raman study from our group [1] it was shown that in the human lens there is an abrupt transition, within $0.3-0.6 \mathrm{~mm}$ from the surface, from a low $( \pm 18 \%)$ protein content in the superficial cortex to a constant high (35-40\%) protein content in the core. In addition it was monitored that the aromatic amino acids tyrosine, tryptophan and phenylalanine are in excess in the central core and that simultaneously there is a significant increase in $\beta$-sheet conformation [7].

The aim of the present study was to investigate whether conformational changes are gradually evolving throughout life or whether they are abrupt as are the changes in protein content. As emphasized in previous papers [12-14] the Raman microspectroscopic set-up, with its sample size of $<1 \mu \mathrm{m}^{3}$, is well-suited for the monitoring of locally defined protein characteristics. 
By using laser light of $660 \mathrm{~nm}$ the excitation of intrinsic fluorescence in human lenses is minimal and there is no adverse effect on the biological samples under investigation.

\section{Materials and Methods}

The Raman spectra were recorded with the Confocal Raman Microspectrometer (CRM). Details about the instrumentation are given by Puppels et al. [15]. A DCM-operated dye laser (Spectra-Physics, model 375B), pumped by an argon-ion laser, was used for the experiments. The laser excitation wavelength was 660 nm. For measurements a $\times 63$ objective was used (Spindler \& Hoyer, NA $=0.85$ ). Peak frequencies were calibrated by means of the spectrum of indene, measured at the same setting of the instrument. Laser power levels at the sample averaged $6 \mathrm{~mW}$.

For the present study, ten human donor lenses varying in age between 17 and 80 years, exhibiting minimal discoloration and no equatorial opacities, were obtained from donor eyes spent for cornea transplantation. The lenses were extracted within $24 \mathrm{~h}$ post-mortem and were fixed in a solution of $0.08 \mathrm{M}$ cacodylate buffered 1\% paraformaldehyde (( $\mathrm{pH} 7.3), 310$ mosmol). In previous studies $[12,13,16]$, it was demonstrated that paraformaldehyde had no significant overall effect on the water/protein content, on the ratios of the tyrosine and tryptophan doublet and on protein secondary structure. Lens slices of about $1 \mathrm{~mm}$ thickness were cut along the optical axis as described earlier [12]. They were put on glass slides and covered with coverglasses of $0.17 \mathrm{~mm}$ thickness. A drop of phosphate-buffered saline was used to prevent them from drying.

The Raman analysis was restricted to the $650-1750$ $\mathrm{cm}^{-1}$ spectral region. This region comprises the most relevant information related to the peptide backbone conformation and to the aromatic and non-aromatic side-chains. Spectra were stepwise recorded along the visual axis of the lens and were obtained at about 75 $\mu \mathrm{m}$ below the surface of the slices. In the outermost anterior $1 \mathrm{~mm}$ of the visual axis, the spectra were obtained at intervals of $100 \mu \mathrm{m}$, followed by intervals of $200 \mu \mathrm{m}$ up to the center of the lens.

The local differences in Raman signals were analysed using the difference spectra approach described before [7]; the spectra at the different positions were scaled for protein content, using the $\mathrm{CH}_{2} / \mathrm{CH}_{3}$ band that was integrated from $1374-1504 \mathrm{~cm}^{-1}$, and subsequently subtracted from the central nuclear spectrum. The analysis of the relative tryptophan content at different sites was approached as follows (see Fig. 1). The areas of the tryptophan (729-781 $\left.\mathrm{cm}^{-1}\right)$ and the $\mathrm{CH}_{2} / \mathrm{CH}_{3}\left(1374-1504 \mathrm{~cm}^{-1}\right)$ bands were integrated in each spectrum. The relative amount of tryptophan

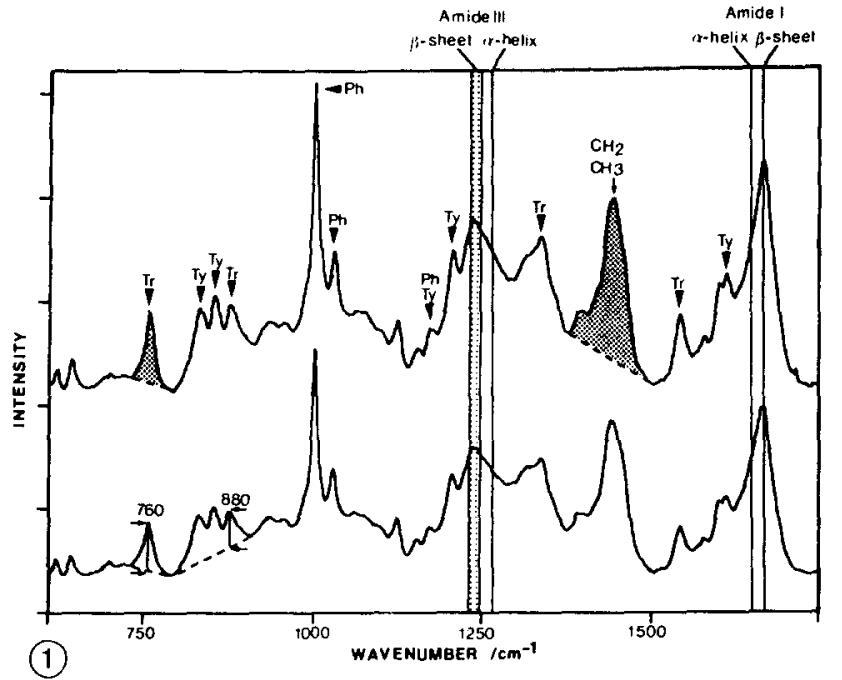

Fig. 1. Examples of Raman spectra taken from a sliced and paraformaldehyde-fixed human donor lens (17 years of age) showing the vibrational peaks and bands studied in this paper and summarizing the basic measurements carried out to quantify the tryptophan content (upper spectrum) and the 'buried' vs. 'exposed' position of tryptophan (lower spectrum). The content of tryptophan was calculated by measuring the shaded area for tryptophan (I(729-781) $\mathrm{cm}^{-1}$ ) and calibrating it for the protein content given by the shaded area of the $\mathrm{CH}_{2} / \mathrm{CH}_{3}$ (protein) band between $\mathrm{I}(1374-1540) \mathrm{cm}^{-1}$. The 'buried' vs. 'exposed' tryptophan was calculated by measuring the peak heights at 760 and $880 \mathrm{~cm}^{-1}$.

calibrated for protein content, is then given by the ratio $\mathrm{I}(729-781) /(1374-1504)$. To analyse the changes in the microenvironment of tryptophan, the peak heights at $880 \mathrm{~cm}^{-1}$ and $760 \mathrm{~cm}^{-1}$ were ratioed (Fig. 1). To facilitate comparison of lenses of varying age the positions along the visual axis were normalized.

To estimate the age-related changes in tryptophan content along the visual axis, the data points up to 0.5 normalized distance indicating the relative tryptophan content (see Fig. 3) were replaced by a least square linear regression line. The slope of this line is taken as an indicator of the rate of inclination of tryptophan along this axis. To analyse whether the age-related differences in tryptophan are identical in core and cortex two most superficial cortical, i.e., nearest to the surface and three central nuclear values were averaged. The changes in tryptophan microenvironment were studied only for the lens core by averaging the $880 / 760 \mathrm{~cm}^{-1}$ ratios for the three most central positions. In all cases age-related differences were statistically tested by linear regression analysis.

\section{Results}

The difference in Raman spectra along the optical axis, are exemplified in Fig. 2 for a young human lens (17 years of age). As also described in a previous paper [7] all tryptophan, tyrosine and phenylalanine signals are found in excess in the lens core. In addition the 


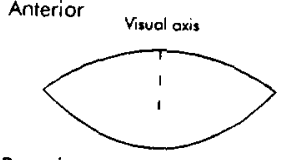

Posterior

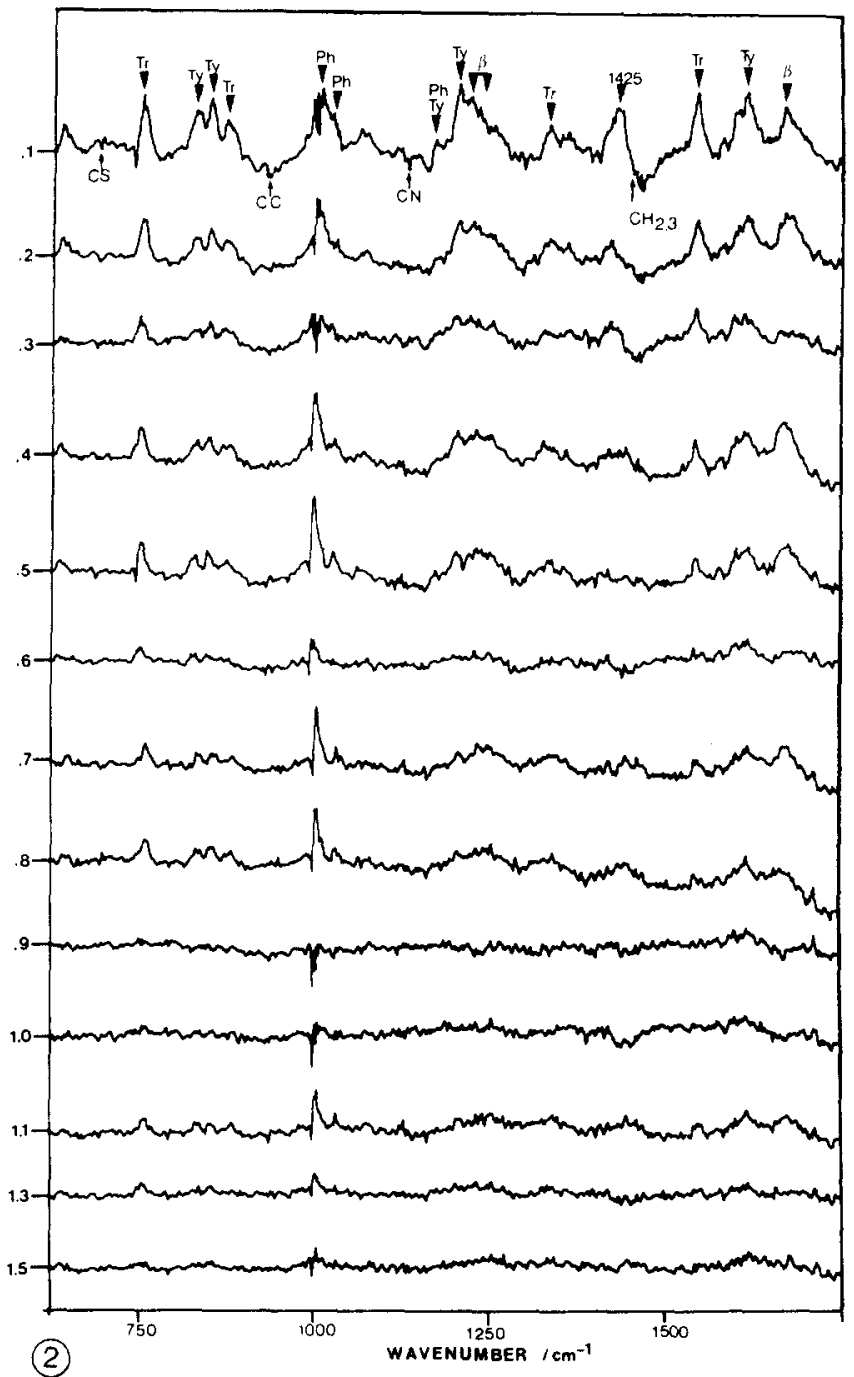

Fig. 2. Example of difference spectra at different axial positions (0.1-1.5 mm below the surface) calculated for a young (17 years of age) donor lens. For this difference spectra approach, the Raman spectra were calibrated for protein content, using the I(1374-1540) $\mathrm{cm}^{-1}$ (protein) band and subsequently subtracted from the central core spectrum (for details, Ref. 7). The vibrations for the peptide bands ( $\mathrm{CS}, \mathrm{CC}$ and $\mathrm{CN}$ ) do not show excess peaks indicating that the backbone is not altered. The most superficial sites show a clear cut excess of all tyrosine, tryptophan and phenylalanine peaks. In addition, the $\beta$-sheet band at $1227-1240 \mathrm{~cm}^{-1}$ and peak at $1675 \mathrm{~cm}^{-1}$ show a significant excess as well. Finally, a peak at $1425 \mathrm{~cm}^{-1}$, not present in the original Raman spectra, appeared. These observations indicate that tyrosine, tryptophan, phenylalanine, $\beta$-sheet and the vibrations responsible for the $I\left(1425 \mathrm{~cm}^{-1}\right)$ peak are more abundant in the core. Note that most excess peaks in this young lens have disappeared at $0.6 \mathrm{~mm}$ below the surface, except for phenylalanine. This latter may be due to an inaccuracy of the wave-number alignment of this sharp phenylalanine peak and the presence of a strong ring vibration of tryptophan at $1016 \mathrm{~cm}^{-1}$.

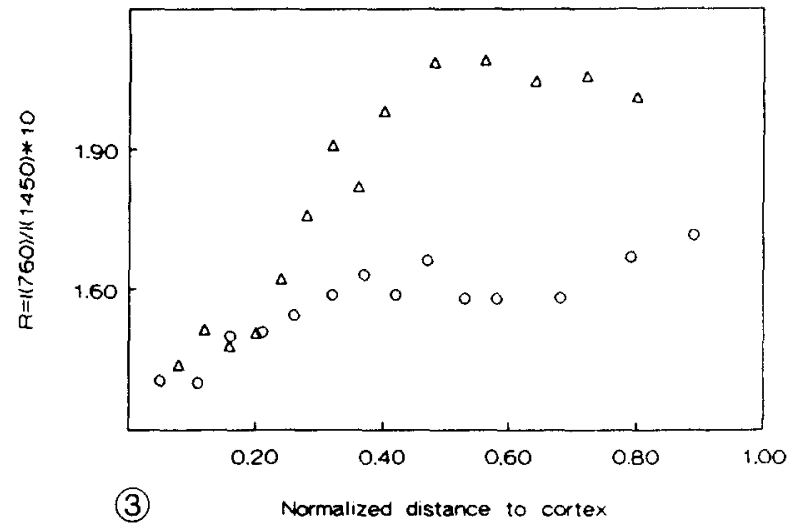

Fig. 3. This figure illustrates the changes in the trypthophan content, indicated by the calibrated ratio $I(760): 1450 \mathrm{~cm}^{-1}$, along the optical axis for a young ( 17 years of age, $O$ ) and an old ( 80 years, $\Delta$ ) human lens. Note that in both lenses the tryptophan content increases towards the core. The increase is more pronounced and more abrupt in the old lens.

$\beta$-sheet signals in the amide-I and amide-II bonds and a peak at $1425 \mathrm{~cm}^{-1}$ proved also to be in excess in the core. At a position of $0.6 \mathrm{~mm}$ below the anterior surface the excess peaks rather abruptly disappear, except for phenylalanine, and a noisy neutral spectrum is obtained. Comparable difference spectra were obtained for all other lenses. The disappearance of excess peaks varied between $0.5-0.9 \mathrm{~mm}$ below the surface. These observations imply that upon maturation and aging the relative content of aromatic amino acids of lens proteins increases and that the $\beta$-sheet conformation becomes more prominent. These changes are not gradual but are completed at a short distance from the anterior surface.

In Fig. 3 the tryptophan-to-protein ratio along the optical axis is exemplified for a young (17-year-old) and old (80-year-old) human lens. In both lenses a significant increase in relative tryptophan content is observed from cortex to core reaching a constant level at about 0.4-0.5 normalized distance from the surface. In the old lens the transition from low cortical to high core levels is much more pronounced. For the other lenses comparable curves were obtained. To analyze whether the increase in tryptophan content becomes more pronounced with age the data points up to $0.5 \mathrm{~mm}$ below the surface were piece-wise replaced by linear regression lines and the slope values were taken as an indicator of the tryptophan gradient. Fig. 4 shows that the gradient significantly increases with age. In order to analyze whether the increase in relative tryptophan content depends on lens age or age of the lens fibers the two outermost and three most central values were averaged. Fig. 5 shows that the relative tryptophan content did not change with age in the cortex but significantly increases with age in the core. 


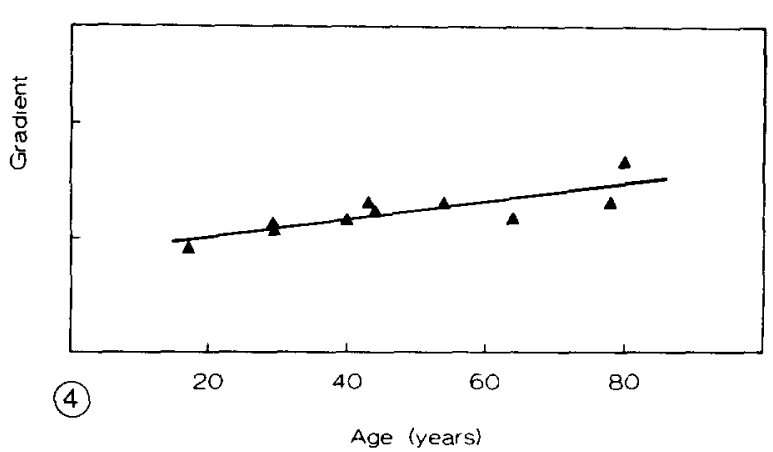

Fig. 4. This figure illustrates the abruptness (gradient) of the increase in tryptophan content, as indicated by the slopes of the least square regression lines calculated from the axial contents (Fig. 3). The gradient significantly increases with age $(R=0.84(10) P<0.01)$.

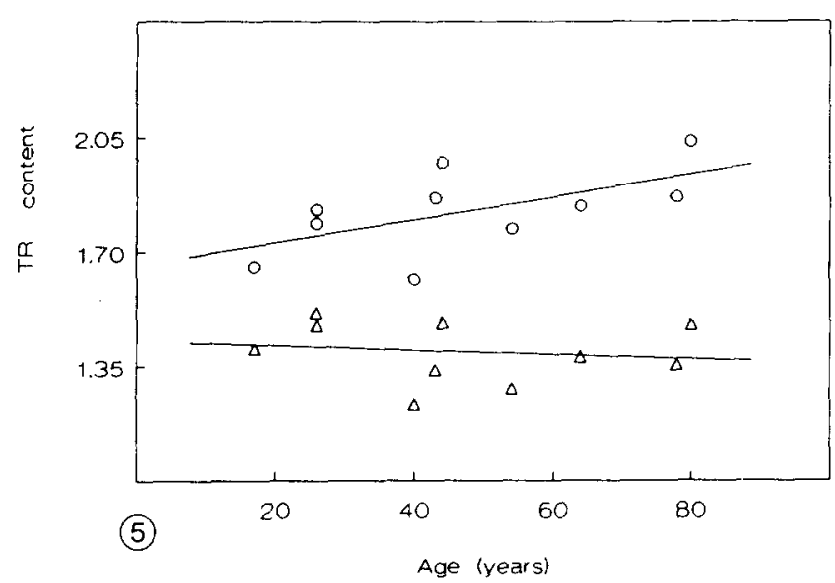

Fig. 5. Tryptophan content in cortex $(\Delta)$ and core $(O)$ as a function of age. Cortical values represent the mean of the two outermost axial positions and core values of the three most central positions. In the cortex no change in tryptophan content was observed. The increase in the core is significant $(R=0.60(10) P<0.05)$.

Fig. 6 shows that the tryptophan environment, indicated by the $\mathrm{I}(880) / \mathrm{I}(760)$ ratio in the core did not change with age.

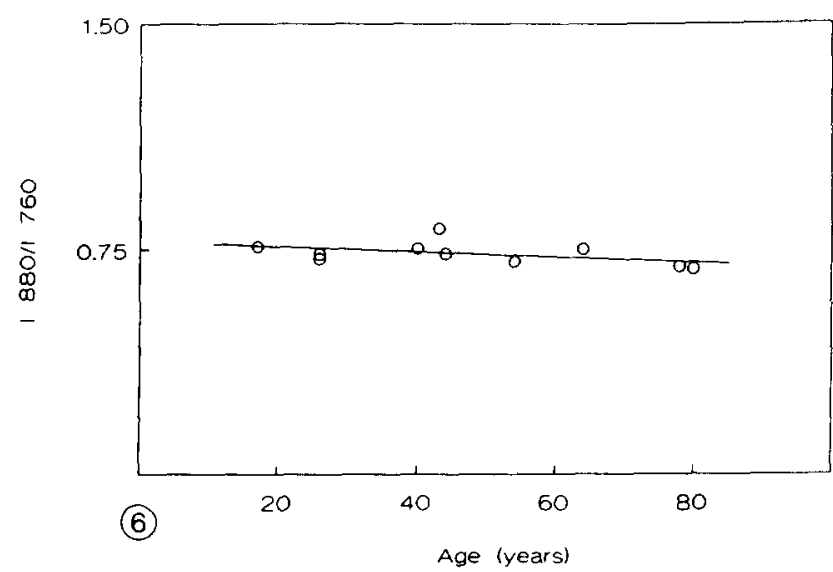

Fig. 6. This figure illustrates the 'buried' vs. 'exposed' position of tryptophan in the core of the lens indicated by the ratio $I(880): 760$ $\mathrm{cm}^{-1}$. No age-related change in this parameter was observed.

\section{Discussion}

In a previous study [7] differences in aromatic side chains and $\beta$-shect conformation of lens proteins bctween core and cortex of the human lens were observed. As outlined in the introduction, the aim of the present investigations was to extend these observations quantitatively and with regard to the site specificity of these differences. For the latter, difference spectra, calibrated for protein content, were measured at precisely defined positions along the optical axis of the lens. The advantages of this approach have been discussed at length [7]. For quantification of changes in the tryptophan, tyrosine and phenylalanine contents and in the amount of $\beta$-sheet conformation, the integrated Raman peaks representing these protein parameters can be related to the $\mathrm{CH}_{2} / \mathrm{CH}_{3}$ vibrations at $1450 \mathrm{~cm}^{-1}$. This peak has been shown to be a reliable protein calibration peak $[9,17,18]$ provided that the proteins do not significantly differ in the number of $\mathrm{CH}_{2}$ and $\mathrm{CH}_{3}$ groups. On account of the amino-acid composition of human $\alpha, \beta$ and $\gamma$ crystallins given by Coghlan and Augusteyn [19] and the differences in $\alpha$, $\beta$ and $\gamma$ content between lens cortex and core given by Kramps [20], the calculated number of $\mathrm{CH}_{2}$ and $\mathrm{CH}_{3}$ groups per 1000 residues was 1650 for the cortex and 1624 for the core; a difference of only $1.6 \%$. Another prerequisite for such approach is, however, that the peaks are well-defined and not contaminated with shoulders of other Raman vibrations. Only the Raman signal for tryptophan at $760 \mathrm{~cm}^{-1}$ fully meets with this prerequisite and therefore was analysed in this study. The ratios of the integrated peak $760: 1450 \mathrm{~cm}^{-1}$ (tryptophan) quantitatively reflects the number of these molecules per unit protein and can be used as such for comparison within and among lenses. The absolute amount, expressed, e.g., as residues per 1000 residues, however, also depends on the stoichiometry between the real concentration of the molecules and the Raman signals. This is linear for the molecules in solutions but unknown for the molecules incorporated in proteins.

The difference spectra, exemplified in Fig. 2, first of all confirm previous observations [7]: an excess of aromatic amino acids in the core as compared to the lens cortex. These observations do not corroborate the observations of Nie et al. [21], who observed a decrease in tryptophan content in human lenses with age. This may be due either to differences in the selection criteria for human lenses or to the fact that we calibrated for protein content and Nie et al. [21] did not. The excess observed in this study most likely reflects the cortex to core shift in crystallin composition and the distinct amino acid contents of the crystallins: an abundance of $\beta$ - and $\gamma$-crystallins in the core [3-5] and an enriched molar ratio of tryptophan and tyrosine of the $\beta$-, and $\gamma$-crystallins [3,8,19,22-24]. McAvoy [25] has reviewed 
the evidence that the abundance of $\gamma$-crystallins in deeper aspects of the lens is the result of the genetic expression of this lens protein at the time of terminal differentiation of lens fibers. The difference spectra, showing that the excess in aromatic amino-acid signals is not present throughout the whole depth of the lens but levels off at about $0.5-0.8 \mathrm{~mm}$ below the surface, are in line with this view. Further support is given by the quantitative observations, exemplified in Fig. 3, that the changes in tryptophan content along the optical axis have a more or less pronounced sigmoid-shaped appearance, indicating a more or less abrupt levelling off between $0.5-0.8 \mathrm{~mm}$ from the surface. This could indicate that the terminal differentiation is about completed at this distance from the surface.

The data summarized in Fig. 5 that aging leads to an increase in tryptophan content of the core indicate that, in addition to terminal differentiation, there must be another factor that affects the tryptophan content especially in the core. Upon aging there is an accumulation of damaged proteins (see e.g., Ref. 5). In addition there is ample evidence for the presence of proteolytic enzymes also in the core of the mature lens. It has already been suggested in 1963 by Van Heyningen and Waley [26] that "lens proteins are broken down to amino acids in vivo by the co-operation of a neutral proteinase (probably an endopeptidase) and an exopeptidase (an aminopeptidase)". The predominant exopeptidase is leucine aminopeptidase, which is also found in human lenses [27]. The reason for the breakdown has tentatively been suggested to be related to the denaturation of lens proteins [26], which is most obvious in the lens core. David and Shearer [28], reviewing the role of proteolysis in the lens, emphasize that endopeptidases play a physiological role in the maturation of lens fibers in, e.g., the breakdown of cytoskeletal proteins, largely absent in mature fibers, and in the degradation of proteins of cell organelles also disappearing during maturation. The two main lens endopeptidases, i.e., the trypsine-like proteinase and the multicatalytic endopeptidase complex preferentially degrade $\alpha$-crystallin peptides and especially the $\gamma$-crystallins proved to be rather resistent to the proteolysis by these enzymes [28]. Since $\gamma$-crystallins are particularly rich in tyrosine and tryptophan (see above), the relative enrichment of this crystallin species in the lens core, due to the possible preferential breakdown of $\alpha$-crystallin upon aging, would explain the ongoing increase in tryptophan with age as observed in this study. The fact that the age-related increase in tryptophan is restricted to the lens core (Fig. 5) further supports this argument. The absence of age-related changes in tryptophan content in the most superficial cortex (Fig. 5) of human lenses can be considered as an indication that normal aging is not accompanied by changes in the read out of the crystallin genes and damage to the crystallin genome. Due to the limitation in methodology outlined above, quantitative conclusions on changes in tyrosine content within the lens and upon aging cannot be made. Close qualitative inspection of the difference spectra, however, makes it rather likely that identical changes for tyrosine occur upon aging as for tryptophan and further strengthen the conclusions given in the last two paragraphs.

A pertinent observation in the difference spectra of all lenses is the peak at $1425 \mathrm{~cm}^{-1}$, indicating that some specific molecule or molecular group is in excess in the core. In normal Raman spectra of proteins this peak is fully masked by the large $\mathrm{CH}_{2} / \mathrm{CH}_{3}$ peak at $1450 \mathrm{~cm}^{-1}$. There are two relevant candidates for this peak: the carboxyl-group of acidic amino acids or the $\delta$-NH-vibration of formylkynurenine [8,29]. Both deamidation of asparagine to aspartic acid $[2,3]$ and photooxidation of tryptophan to $\delta$-H-formylkynurenine $[30,31]$ have been shown to occur in the human lens during aging. The present results additionally support the biochemical evidence for these processes and moreover show that these changes are most prominent in the superficial layers, i.e., during the early life span of the proteins. Which of these candidates for the excess vibration at $1425 \mathrm{~cm}^{-1}$ is indeed present in the aged lenses needs to be verified in more detailed model studies using isolated crystallins of cortex and core.

Although the amide-III and amide-I bands at $1227-$ $1264 \mathrm{~cm}^{-1}$ and $1660-1673 \mathrm{~cm}^{-1}$ are complicated it has been shown that a difference spectra approach allows conclusions on the $\alpha$-helix and $\beta$-sheet configuration of proteins which are in agreement with studies using circular dichroism, optical rotary dispersion and X-ray crystallography [7]. The present difference spectra also confirmed the previous observations [7] that core proteins have a more pronounced antiparallel $\beta$-pleated sheet conformation than cortical proteins. It has been shown that $\alpha$-crystallins are characterized by a very minor $\alpha$-helix configuration and that $\gamma$-crystallins in solution have a substantial (20\%) $\alpha$-helix configuration [32-36]. Since in addition the $\beta$ - and $\gamma$-crystallins proved to be more abundant in the lens core (see above), the increased $\beta$-sheet conformation in the core can only be explained by assuming a post-translational shift in conformation from $\alpha$-helix to $\beta$-sheet. Since the difference spectra show a disappeareance of the excess-peaks for the $\beta$-sheet band $\left(1227-1340 \mathrm{~cm}^{-1}\right)$ and peak $\left(1673 \mathrm{~cm}^{-1}\right)$ at about $0.5-0.9$ normalized distance below the surface, it can be tentatively concluded that this conformational shift is most prominent in superficial layers. Whether aging leads to further increase in $\beta$-sheet conformation cannot be concluded from this study.

As rationalized by Kitagawa et al. [37], the $I(880): I(760) \mathrm{cm}^{-1}$ ratio reflects changes in the mi- 
croenvironment of tryptophan: 'buried' tryptophan gives a relative intense peak at $880 \mathrm{~cm}^{-1}$ while 'exposed' tryptophan shows a relative weak peak at this spectral position. Data in literature on local and agerelated changes in the microenvironment of tryptophan are controversial. A decrease in this ratio upon aging has been observed in ICR, cac and Emory mice $[10,11,38]$ and it was concluded that tryptophan becomes more 'exposed' with age. No changes in this ratio were observed between nuclear and cortical proteins in rabbits [14] and in cold cataract [39]. The relevance of the $I(880): I(760) \mathrm{cm}^{-1}$ ratio is based on the assumption that the $880 \mathrm{~cm}^{-1}$ signal reflects the 'exposed' vs. 'buried' position of tryptophan and that the $760 \mathrm{~cm}^{-1}$ signal is independent of this. The I880): $\mathrm{I}(760) \mathrm{cm}^{-1}$ ratio does not show a significant age-related shift, indicating that the 'buried' or 'exposed' position of tryptophan in human lens proteins is not affected by age in the lens core of the human lens (Fig. 6).

In a previous study from our group [1] it was shown that the well-known increase in protein content of the human lens from cortex to core is not gradual but rather abrupt reaching a constant level at about 0.2-0.6 $\mathrm{mm}$ below the surface. The present study additionally shows that maturational shift in tryptophan content, and possibly also of tryptophan and phenylalanine, the post-tranlational shift towards a more pronounced $\beta$ sheet conformation and the presence of the $1425 \mathrm{~cm}^{-1}$ peak are most prominent in superficial layers, i.e., during the early life span of the crystallins. Independent studies on the physiology $[39,40]$, the lipid composition [41] and the ultrastructure [42,43] of lens membranes have shown a cortex to core change from membranes with normal permeability properties, normal cholesterol to phospholipid ratios and a normal architecture to non-leaky, high-cholesterol-containing membranes with a 'degenerate' architecture. This shift is rather abrupt and completed at $0.3-0.7 \mathrm{~mm}$ below the surface. In addition it is known that the lens has a low metabolic rate [44]. On account of this accumulating evidence it is attractive to postulate that the lens is a two compartment organ comprising a small biochemically and physiologically active cortical zone and a large relative inert core. This postulated relative inertia' of the lens core would make it rather insensitive to age-induced changes, probably apart from some extra light-induced damage to proteins. This is in support of the epidemiologically and clinically observed preponderance of cortical cataracts and the steady non-vision-disturbing increase in discoloration and light scatter of the lens core.

The present systematic confocal Raman microspectroscopic analysis of human lenses allows the conclusion that upon aging the crystallins undergo maturational and post-translational changes. In the 'older' lens core the aromatic amino acids tryptophan, tyrosine and phenylalanine are always in excess, as compared to the 'younger' lens cortex, Moreover, an increase in $\beta$-sheet conformation was observed from outside to inside. Within $0.4-0.9 \mathrm{~mm}$ from the surface these changes were largely completed, indicating that they occur in the early life span of the crystallins. In addition, it was observed that the tryptophan content increases with age in the core but not in the cortex and that the 'buried' vs. 'exposed' position of tryptophan did not alter upon aging.

\section{Acknowledgements}

The authors are grateful to Dr. E. Pels and her co-workers of the Cornea Bank Amsterdam for collecting the lenses and to Mr. B. Willekens for technical assistance. The secretarial assistance of Mrs. A. de Wolf and Mrs. H. Fopma-Bonnes is gratefully acknowledged. This study was carried out within the framework of the European Economic Community Concerted Action on Cellular Aging and Diseases 'Eurage'. We are indebted to the 'Stichting het Haagsch Oogheelkundig Fonds' for their financial support regarding the dye laser used in this study.

\section{References}

1 Siebinga, I., Vrensen, G.F.J.M., De Mul, F.F.M. and Greve, J. (1991) Exp. Eye Res. 53, 233-239.

2 Harding, J. (1981) in Molecular and Cellular Biology of the Eye Lens (Bloemendal, H., ed.), pp. 327-365, Wiley, New York.

3 Hoenders, H.J. and Bloemendal, H. (1981) in Molecular and Cellular Biology of the Eye Lens (Bloemendal, H., ed.), pp. 279-326, Wiley, New York.

4 Hoenders, J. and Bloemendal, H. (1983) J. Gerontol. 38, 278-286.

5 Spector, A. (1985) in The Ocular Lens (Maisel, H., ed.), pp. 405-438, Marcel Dekker, New York.

6 Yu, N-T., DeNagel, D.C., Ho, D.J-Y. and Kuck, J.F.R. (1987) in Biological Applications of Raman Spectroscopy, Vol. 1 (Spiro, T.G., ed.), pp. 47-80, Wiley, New York.

7 Siebinga, I., Vrensen, G.F.J.M., Otto, C., De Mul, F.F.M., Puppels, G.J. and Greve, J. (1993) Exp. Eye Res. 54, 759-767.

$8 \mathrm{Yu}, \mathrm{N}-\mathrm{T}$. and East, E.J. (1975) J. Biol. Chem. 250, 2196-2202.

9 Ozaki, Y., Mizuno, A., Yoshiura, M., Iwamoto, T. and Iriyama, K. (1983) Biochemistry 22, 6257-6259.

10 Itoh, K., Ozaki, Y., Mizuno, A. and Iriyama, K. (1983) Biochemistry $22,1773-1783$.

11 Ozaki, Y., Mizuno, A., Itoh, K. and Iriyama, K. (1987) J. Biol.Chem. 262, 15445-15551.

12 Bot, A.C.C., Huizinga, A., De Mul, F.F.M., Vrensen, G.F.J.M. and Greve, J. (1989) Exp. Eye Res. 49, 161-169.

13 Huizinga, A., Bot, A.A.C., De Mul, F.F.M., Vrensen, G.F.J.M. and Greve, J. (1989) Exp. Eye Res. 48, 487-496.

14 Schyns, M.W.R.J., Huizinga, A., Vrensen, G.F.J.M., De Mul, F.F.M. and Greve, J. (1990) Exp. Eye Res. 50, 331-333.

15 Puppels, G.J., De Mul, F.F.M., Otto, C., Greve, J., Robert-Nioud, M., Arndt-Jovin, D.J. and Jovin, T.M. (1990) Nature 347, 301-303.

16 Mason, J.T. and O'Leary, T.J. (1991) J. Histochem. Cytochem. 39, 225-229.

17 Fasman, G.D., Itoh, K., Liu, C.S. and Lord, R. (1978) Biopolymers $17,125-143$. 
18 Tu, A.T. (1982) in Raman spectroscopy in biology; Principles and applications, Wiley, New York.

19 Coghlan, S.D. and Augusteyn, R.C. (1977) Exp. Eye Res. 25, 603-611.

20 Kramps, J.A. (1977) Ph.D. Thesis, University of Nijmegen.

21 Nie., S., Bergbauer, K.L., Kuck, J.F.R., Jr. and Yu, N-T. (1990) Exp. Eye Res. 51, 619-623.

22 Bjork, I. (1964) Exp. Eye Res. 3, 254-261.

23 Croft, L.R. (1972) Biochem. J. 128, 961-970.

24 Zigler, J.S. and Sidbury, J.B., Jr. (1977) Ophthalmic Res. 8, 92-98.

25 McAvoy, J.W. (1981) in Mechanism of Cataract Formation in the Human Lens (Duncan, G., ed.), pp. 7-46, Academic Press, London.

26 Van Heyningen, R. and Waley, S.G. (1963) Biochem. J. 86, 92-101.

27 Taylor, A., Surgenor, T., Thomson, D.K.R., Graham, R.J. and Oettgen, H. (1984) Exp. Eye Res. 38, 217-229.

28 David, L.L. and Shearer, T.R. (1989) Lens Eye Tox. Res. 6, $725-747$.

29 Dollish, F.R., Fately, W.G. and Bentley, F.F. (1974) Characteristic Raman Frequencies of Organic Compounds, Wiley, New York.

30 Zigman, S. (1985) in The Ocular Lens (Maisel, H., ed.), pp. 301-347, Marcel Dekker, New York.

31 Dillon, J. (1985) in The Ocular Lens (Maisel, H., ed.), pp, 349-366, Marcel Dekker, New York.
$32 \mathrm{Li}, \mathrm{L}-\mathrm{K}$. and Spector, A. (1967) J. Biol. Chem. 242, 3234-3236.

$33 \mathrm{Li}, \mathrm{L}-\mathrm{K}$. and Spector, A. (1974) Exp. Eye Res. 19, 49-57.

34 Armand, G., Balazs, E.A. and Testa, M. (1970) Exp. Eye Res. 10, $143-150$.

35 Horwitz, J., Kabasawa, I. and Kinoshita, J.H. (1977) Exp. Eye Res. 25, 199-208.

36 Stiuso, P., Ragone, R. and Colonna, G. (1990) Biochemistry 29, 3929-3936.

37 Kitagawa, T., Azuma, T. and Hamaguchi, K. (1979) Biopolymers $18,451-465$.

$38 \mathrm{Ozaki}$, Y., Mizuno, A., Itoh, K., Matsushima, S. and Iriyama, K. (1987) Appl. Spectrosc. 41, 597-604.

39 Mizuno, A., Ozaki, Y., Itoh, K., Matsushima, S. and Iriyama K. (1984) Biochem. Biophys. Res. Commun. 119, 989-994.

40 Rae, J.L. and Matthias, R. (1985) in The Ocular Lens (Maisel, H., ed.), pp. 93-121, Marcel Dekker, New York.

41 Duncan, G. and Jacob, T. (1984) in The Eye, Vol. 1b. (Davson, H., ed.). pp. 159-206, Academic Press, Orlando.

42 Hockwin, O. and Ohrloff, C. (1981) in Molecular and Cellular Biology of the lens (Bloemendal, H., ed.), pp. 367-413, Wiley, New York.

$43 \mathrm{Li}, \mathrm{L}-\mathrm{K}$., So, L. and Spector, A. (1985) J. Lipid Res. 26, 600-609.

44 Van Marle, J., Vrensen, G.F.J.M. and Van Veen, H. (1991) Top. Aging Res. Europe 15, 123-135.

45 Vrensen, G.F.J.M., Van Marle, J., Van Veen, H. and Willekens, B. (1993) Exp. Eye Res. 54, 433-446. 